\title{
ENHANCING FACTORS OF BUSINESS INTERNATIONALIZATION - A MODEL FOR PORTUGUESE SMES
}

\author{
C. Azevedo Lobo ${ }^{1}$, A.T. Ferreira ${ }^{2}$, S.A. Cordeiro ${ }^{3}$, C. Costa-Lobo ${ }^{2}$ \\ ${ }^{1}$ Univ. Portucalense, Portucalense Institute for Legal Research - IJP; GOVCOPP - UA \\ (PORTUGAL) \\ ${ }^{2}$ Univ. Portucalense, Institute for Cognitive and Behavioral Neuropsychology Neurosciences \\ - INPP (PORTUGAL) \\ ${ }^{3}$ Institute for Cognitive and Behavioral Neuropsychology Neurosciences - INPP \\ (PORTUGAL)
}

\begin{abstract}
Nowadays, firms need to engage in a continuous innovation process and constantly restructure their operations to meet the requirements of national but, most of all, international competition. Failure to act internationally may lead to a loss of market opportunities, but also to a more severe inability to survive in the long run. Firms must find new ways to develop a competitive advantage, which entails searching for and acquiring new skills, resources and capabilities. Knowledge is an important strategic resource due to its impact on firms' competitive capacity. In many instances, firms, including international new ventures, may access those resources, including the market-specific knowledge, through alternative ways of governance, such as "industrial networks". In this work, through an empirical study with 320 Portuguese international firms, a Theoretical Model that measures the enhancing factors of business internationalization is presented, with evidence of the importance of Networks, of "Specific Skills of its workers", "International Experience of its workers" and of "Entrepreneurial Propensity and to take risks from workers and top management team", in accordance to Human Capital Theory, Social Cognitive Theory, International New Ventures Theory, and the Population Ecology Approach.
\end{abstract}

Keywords: Internationalization, Networks, Entrepreneurial Skills, INV, SMEs, Career.

\section{INTRODUCTION}

The study of companies' internationalization takes nowadays one increasingly importance. Internationalization has become more than a survival issue. In a changing world, with the progressive liberalization of world trade, the international expansion has been one of the responses from companies, to the increased competition, to the threats and their survival. According to [1] international business was for a long time dominated by large companies and smaller companies tended to remain local or regional. Traditional theories of internationalization focused mainly multinational companies, giving less importance to entrepreneurs with their small businesses. However, the development of the business world has been breaking all boundaries, with the increasing internationalization of companies, not dependent to the size, activity sector or geographical area of origin [2]. There is now a growing need to understand internationalization in the context of entrepreneurship, as it existed in the context of large multinationals. Knowledge of "who", "when" and "why" companies become international, have become important research topics in the area of International Entrepreneurship. According to [2], franchising, strategic alliances and other forms of cooperation are among the various forms of internationalization that show the greatest growth, which reflects the tendency of the type of competition of companies that have been displacing from the direct competition to the collaboration, from the individual strategy to the network strategy. Integration into a network allows access to knowledge and a broad set of physical, technical, financial and reputation resources that facilitate adaptation to the various economic, political, legal and cultural dimensions [3]. International environments can facilitate internationalization by reducing the psychic distance perceived by companies [4]. Nowadays, companies have to find new ways to develop competitive advantages, such as the search and acquisition of new skills, resources and capabilities [5]. In many cases, companies can obtain these resources, including specific knowledge of the market or through alternative forms of management, such as industrial networks. Recent empirical evidences [6] provides important insights on the internationalization of new business, showing that younger firms are able to compensate their limited experiential learning at company level, through learning based on 
previous experiences of the management team (congenital learning), and through inter-organizational relationships (vicarious learning), also suggesting that the age and size of the company should be analyzed, but without being a restriction to the beginning of internationalization. By other size, [7] and [8] consider that governmental and associative incentives have for most companies a positive effect in the beginning of internationalization.

In the literature on business internationalization, a large number of scientific studies focus on the determinants of internationalization, more specifically, the relationship with the success / failure of internationalization. In this perspective, the company is treated as a "black box", as a set of factors that will lead to a certain result. This paper presents a study focused on the perspective of the entrepreneur and company manager, as well their views on the issue of internationalization, more specifically, about the factors that contributed to make possible the company entry into markets beyond of the domestic market, as well its entrepreneurial initiatives of early internationalization. It's about the entrepreneur, the company's characteristics, market and employees that focuses mainly this analysis.

Based on the literature review, it is important to know what factors have potentiated the internationalization of Portuguese companies, that is, to determine which variables act as "facilitators/ enhancers" of the internationalization strategy of Portuguese companies. For example, verify if factors such as the "relational network", "entrepreneurial personal characteristics and acquired skills of entrepreneurs"; the "international experience of employees", or other variables such as "company age"; its "size"; the "incentives/support for internationalization"; the "distance or physical and psychological proximity" can act as agents that enhance the internationalization process of the company. The main objective is to find and confirm structural patterns among variables. That is, to know that latent factors are responsible for the behavior of the manifested variables specified according to our theoretical model. The statistical techniques used allow us to define the latent factors that represent the entrepreneurial variables that enhance entrepreneurial internationalization, as well to evaluate the quality of adjustment of this theoretical measurement model. Based on the objectives, the following research questions were defined: a) what are the variables that enhance the internationalization of Portuguese companies? b) What is the Theoretical Model that best fits the correlational structure observed among the manifested variables (the factors driving entrepreneurial internationalization)?

\section{LITERATURE REVIEW}

Many of the theories related to business strategy and internationalization, attach importance to learning and knowledge, considering them central characteristics of companies but especially of entrepreneurs and their collaborators. According to the Human Capital Theory, the availability of qualified human resources is essential for the performance of companies and has a positive effect on the internationalization of the same. Also according the perspective of Population Ecology, entrepreneurs are portrayed as individuals capable of identifying opportunities and finding the resources to explore them. The theory of International New Ventures (INV) also reinforces the importance that these factors have for the "early" internationalization of companies against the socalled behavioural view of internationalization. This theory emphasizes the importance of relational networks and vicarious learning as a way for companies to acquire knowledge about the external market, but also emphasizes congenital learning (experience and individual knowledge) as a way to recognize the importance of relational alliances and networks to the beginning of internationalization. It is clear, therefore, that the elements common to the most recent approaches to internationalization are the importance of knowledge and relational networks, which we have chosen as the basic theoretical model for this work.

\subsection{Relational Network Theory}

According to the network theory, depending on the position occupied by a company in the network, this will define its range of opportunities and constraints and thus develop its strategies. In this way the phenomenon of the internationalization of the company can be seen as the establishment and development of positions in relation to other partners belonging to foreign networks [9]. [10] refer that these relationships have a strong impact on market selection, as well the facility with which they identify and exploit opportunities. According to [11] the cooperation networks favor the competitiveness of companies and are an important instrument to support the internationalization of SMEs (Small and Medium Enterprises). Networks provide companies with a set of resources and 
information about the market and customers, increasing the chances of survival and success. The contacts obtained in the network allow companies to have access to resources that they do not have and could not access otherwise.

[4] affirms that networks are more important to SMEs because of the lack of human, technical and financial resources to be able to internationalize their operations on their own.

For [11] and [12], SMEs are characterized by their flexibility and adaptability and innovation, but the establishment of relationships in international markets requires more skills.

\subsection{Human Capital Theory}

According to [13], human capital is fundamental to economic growth and entrepreneurial opportunities. In relation to internationalization, human capital consists of the knowledge, skills, talent and experiences used to provide value to the company. Most studies focus on human capital as a company resource, but cannot find a direct relationship between human capital and business internationalization. The Resource Based View (RBV) asserts that the resources specific to the company result in a sustainable competitive advantage, creating resources that are valuable, rare, inimitable and non-substitutable [13] [14]. The human capital resource includes "training, experience, critical capacity, intelligence, relationships and individual perception of the managers and employees of a company" [13]. For these authors, human capital theory suggests that companies with a higher degree of human capital developed through the availability of employees with higher education and personal experience achieve a better performance.

\subsection{Socio-cognitive career theory: its intersections with the specific competencies of employees}

The central variables of the socio-cognitive career theory have attracted a large number of researches in recent years. Meta-analytic review studies have identified a substantial number of researches that indicate that cognitive variables support the understanding of work behaviour in a professional setting at different stages of career development [15] [16] [17] [18]. [19] argue that the study of career adjustment should consider social conditions in learning opportunities, interpersonal relations (e.g. support) and also in results that individuals anticipate as a consequence of their choice, involvement and persistence in certain activities. The socio-cognitive theory of the career is based on the way in which the individuals negotiate marks and obstacles of development, relevant for the future of their careers [20]. This theory analyses dynamic and specific, personal and contextual dimensions.

The results of this line of research have led to the conclusion that specific measures of self-efficacy are predictive of career interests, exploratory behaviour and career choice, as well, the existence of causal relationships between self-efficacy measures and Performance and occupational interests [16] [17] [18]. According to the socio-cognitive model of career interests formation, self-efficacy and expectations of results contribute favourably to career interests. The interest in an activity is increased in situations in which individuals perceive themselves as competent in this activity and have positive expectations of results. As interests emerge, these, together with expectations of self-efficacy and expectations of result, encourage intentions to maintain involvement in certain activities [21]. Expectations for self-efficacy and expectations of results are understood to be responsible for career interests, which in turn tend to promote the intentions of going a particular career path, intentions, which are congruent with individual interests.

The social-cognitive career perspective [21] emphasizes personal self-efficacy variables, the result of expectations, goals, and their interaction with environmental and personal variables (social support) in the context of career development. [22] characterize the relationships between self-efficacy, achievement, and interests, assuming that a complex set of factors (culture, gender, socio-structure, health status) operating simultaneously influences cognitions, abilities and career possibilities.

Career choice is understood as a two-way path, conditioned in part by the receptivity of the environment and judgments about the individual's ability to meet training and performance requirements [21]. In this perspective, the contextual influences are divided into two generic types, based on the moment they occur, during the process of choice. The first type includes the most distant influences (e.g. culture, types of career models, capacity building opportunities) the second type refers to environmental influences that manifest during the active phases of the choices making process (e.g. emotional and financial support). The analysis of this model reveals the more distant effects of 
contextual variables, in the acquisition of expectations of self-efficacy and results. The analysis of this model reveals the more distant effects of contextual variables, in the acquisition of expectations of self-efficacy and outcome. According [21], career interests are more probable to become objectives, and the objectives are more probable to be implemented when individuals experience strong environmental support and weak barriers to their paths career opportunities. The relationship between interests and objectives, and the relationship between objectives and actions are expected to be stronger when environmental conditions are favourable. Environmental factors may facilitate or complicate the implementation of the choice process, regardless of how individuals follow the options through their primary interests. In summary, based on the socio-cognitive theory of Bandura [15], it is possible to specify the influence of contextual, personal and learning variables in the decision processes, according to the following propositions: (a) beliefs of self-efficacy influence directly and indirectly objectives and choices; (b) expectations influence directly and indirectly objectives and choices; and (c) interests influence directly and indirectly choices.

\subsection{Population Ecology Approach}

Defenders of the Population Ecology approach argue that external forces such as competition, leading the entrepreneur to look for other opportunities in foreign markets in order to survive. To obtain a better understanding of the entrepreneur's decision to internationalize, we must understand his mind and entrepreneurial characteristics [23]. Research on entrepreneurship has identified a number of traits associated with entrepreneurs, such as the need for achievement, the propensity to take risks, the locus of control or self-confidence, and tolerance to uncertainty contexts [23]. Family history has also been presented in the literature to explain the motivations of the individual to start a business [23]. In entrepreneurship literature, entrepreneurs are characterized as those individuals who are able to identify an opportunity and find the resources to explore it [23] [24]. Thus, the entrepreneur's decision to access the external market through market analysis, to detect new opportunities and to organize the resources to exploit them, should be valued as part of the entrepreneurial process [25] [23].

\subsection{International New Ventures (INV) Theory}

All these perspectives and theories presented before are joined in the International New Ventures (INV) Theory. With regard to the importance of learning and knowledge for companies with diminutive international experience, theories previous to the middle of 1990s offered limited ability to explain how and for what reasons, some companies began to operate successfully across national boundaries, such as Born Globals [25] [26]. [27] changed the thinking about the internationalization process, challenging the broadly accepted [28] [29] stages perspective (stage theory), and conceived the Internationalization as slow. The research about INV challenged the idea that new or small companies could not be internationalized early [27] [30]. Since then, a growing flow of research about INV has required understanding the causes, processes, and results of the decision to arrive foreign markets early. A common thread concerns to the role of learning and knowledge [31] [30]. Organizational knowledge was a central explanation for internationalization in stage models [28] [29], but [25] recognized that individual factors such as experiential knowledge of the external market (or international experience) could also influence the speed and the beginning of internationalization. Thus, knowledge has a fundamental role in the stages perspective and in the approach of INV, but in a different way. The stages perspective uses the behavioural theory of the company to argue that the lack of organizational knowledge about the external markets blocks the company from inserting and expanding internationally [29]. This perspective is denominated by [32] as behavioural view of internationalization. By other side, the perspective INV emphasizes the role of individual knowledge [25] to argue that international ventures do not need organizational experiences, routines or skills to insert in the outside market early. The individual organizational knowledge about markets outside the company can help the company to overcome the incremental processes suggested by the Stages perspective [25]. To this approach, [5] call it a strategic choice view. The growing popularity of INV amplified the literature about the start of internationalization.

We better explain each of these types of learning/knowledge that have gained notoriety in recent theories of business internationalization. 


\subsection{Experiential learning}

Experiential learning was seen as the most generalized type of learning in organizations, and gradual international experience was the central mechanism that conduced the internationalization process in [28] theory. However, [33] reflect about the effects of experiential learning in the domestic market and the decision to internationalize the company's operations early. The authors find that a greater intensity of domestic learning processes (before access to the outside market), less probable are the start of the early internationalization. This result conflicts with the theory that suggests that learning and business orientations that include learning components can induce to an early internationalization [34]. Perhaps the specific focus of learning is fundamental. That is, as empirically demonstrated by [35], domestic learning guidelines alone may not lead to internationalization, but only when combined with other factors that favour international learning, such as previous international experiences or learning. Different to the existing multinational corporations, the new ventures do not have the possibility of using experiential learning at company level. Recent empirical evidence [6] offers important insights on the internationalization of new business, showing that younger enterprises are able to compensate for their limited experiential learning at company level, through learning from previous experiences of management team (congenital learning) and through inter-organizational relationships (vicarious learning).

\subsection{Congenital learning}

Several theoretical articles argue that companies whose managers have prior international experience are more prone to internationalize early than those without such experience [36] [10] [25]. The main argument is that founders with previous international experience are more conscious of international opportunities, more capable of assessing opportunities, and more disposed to seek such opportunities. [36] state that congenital knowledge awakens managers to international opportunities and causes them to attribute lower costs to the internationalization process than managers without such experience.

[10] also conclude that previous international managerial experience "can have a strong effect on internationalization. The empirical evidence allows concluding that the previous international experience significantly affects the probability of beginning the internationalization and the rapidity to develop foreign partnerships".

\subsection{Vicarious Learning}

In this respect, it has been observed that many new companies have become internationalized as part of a network, where strategic alliances play a prominent role [37]. Alliance dependency is so critical that the term "liability of outsider-ship" has been used to describe the disadvantages resulting from internationalization in the default of an appropriate network [10]. According to [5], vicarious learning (learn by observing others) has a central role in the decision to internationalize the company's operations early. While some articles use the term "vicarious," many others point to learning as a mechanism that influences the onset of internationalization decisions, through imitation or working alongside others. A central argument in these articles is that the presence or development of foreigner's contacts activates opportunities for the beginning of internationalization [36].

There is also evidence in some empirical studies that show that smaller firms, with deficient resources and experience to access foreign markets, prefer to access through shared solutions [38]. For these companies, entering the outside market alone is a risky option that requires a large volume of resources and is not always possible in smaller companies.

\section{METHODOLOGY}

In this study is intended to evaluate the entrepreneurs' perceptions, in order to determine which variables they consider to enhance of the internationalization of their companies. Based on the literature review, it is important to know how companies were able to achieve internationalization, specifically, what factors facilitated the internationalization process. To this end, was prepared a questionnaire entitled: Factors that contribute to the effectiveness of corporate internationalization. This questionnaire was sent by e-mail to exporting companies and/or interested in exporting through the AICEP-Portugal global database. To validate the form and content of the questionnaire, the instrument was pre-tested in a total of four companies. The pertinence of the variables, retired from 
the literature review, was evaluated through interviews with specialized researchers. A total of 320 responses were obtained: 186 from companies operating in the services sector, 129 in the industrial sector, and 5 agricultural companies. It should be noted that $86 \%$ of the companies are SMEs, which according to the Eurostat definition (Structural Business Statistics) have less than 250 employees. Almost half of the companies considered in this study can be considered early internationals or INV, since they have internationalized at most with 6 years of age [5].

Given the nature of the database to be explored and the research objectives, an inferential analysis was performed using the confirmatory factor analysis methodology. The objective was to confirm the structural patterns, that is, to know if the latent factors found in the Exploratory Factorial Analysis (EFA) previously obtained are responsible for the behaviour of the manifest variables specified according to our theoretical model. This technique allowed appropriate a measurement model (theoretical) to the correlational structure observed between the manifested variables.

\subsection{Confirmatory Factorial Analysis (CFA)}

While EFA is an exploratory method that should be used when there is no previous information about the factorial structure which may explain the correlations between the manifest variables and where the latent factors explain the correlations between manifest variables and the technique allows the exploration of structural patterns (i.e. which are the latent factors are responsible for the behaviour of which manifest variables). Confirmatory Factorial Analysis (CFA) is a confirmatory method that is used when there is previous information about the factorial structure that needs to be confirmed. The CFA confirms structural patterns, that is, if certain latent factors are responsible for the behaviour of certain specific variables according to agreement, for example, with a certain theory. Also the CFA, in the context of the structural equation analysis, is generally used to evaluate the quality of adjustment of a theoretical measure model to the correlational structure observed between the manifested variables [39].

\subsection{Statistical Analysis}

The factorial validity of the three dimensions considered in the EFA previously performed was evaluated through the confirmatory factorial analysis with the AMOS software (v. 20, SPSS INC, Chicago, IL) as described in [39]. The composite reliability and average variance extracted by each factor were evaluated as described by [40] and [39]. The square distance of Mahalanobis (DM $\left.{ }^{2}\right)$ evaluated the existence of outliers, and the normality of the variables was evaluated by the univariate and multivariate coefficients of asymmetry (sk) and kurtosis (ku). Anyone variable presented Sk and $\mathrm{Ku}$ values Indicators that put in question the Normal distribution $(|\mathrm{Sk}|<3$ and $|\mathrm{Ku}|<10)$ [39]. Some observations presented $\mathrm{DM}^{2}$ values that suggested that these observations were outliers, so the confirmatory factor analysis was done without these observations. The overall adjustment quality of the factorial model was made according to the indexes and respective reference values described by [39] (X2 / df, IFC, GFI, RMSEA, P [rmsea s.05] and MECVI). The quality of the local adjustment was evaluated by the factorial weights and the individual reliability of the items. The adjustment of the model was made from the modification indexes $(>11 ; p<.001)$ produced by AMOS and based on theoretical considerations.

\section{RESULTS}

The tri-factorial model of the Factors Inducing the Business Internationalization adjusted to a sample of 320 companies revealed a poor quality of adjustment $\left(X^{2} / d f=3.173, C F I=0.924, G F I=0.963\right.$, RMSEA $=0.083, \mathrm{P}$ [rmsea $\leq .05]=0.015$ and $\mathrm{MECVI}=0.294)$. After eliminating six outliers observations, and removing the contact network item in the host country, whose modification index suggested a strong correlation of the error with a different factor than the one initially suggested (Knowledge), it was possible to obtain a good adjustment $\left(X^{2} / d f=1.674, C F I=0.981, G F I=0.984\right.$, RMSEA $=0.047, \mathrm{P}[\mathrm{rmsea} \leq .05]=0.513$ e $\mathrm{MECVI}=0.172)$ in support of the validity Factorial of the presented model. The composite reliability of the factors proved to be adequate, with 0.72 for Knowledge, 0.77 for Endogenous Characteristics and 0.89 for Market Characteristics. The Average Extracted Variance (AEV), an indicator of the convergent validity of the factors, was also adequate, being 0.5 for the Knowledge, 0.64 for the Endogenous Characteristics and 0.81 for the Market Characteristics. 
Figure 1 presents the values of the standardized factor weights and the individual reliability of each of the items in the simplified model. The discriminant validity of the factors was evaluated by comparing the AEVs with the squares of the correlation between factors. The values of $A E V c=0.5$ and $A E V c e=$ 0.64 are higher to $r^{2}{ }_{c}$, ce $=0.05$, so we can state that the two factors (Knowledge and Endogenous Characteristics) have discriminant validity. In a similar way, it is possible to demonstrate the discriminant validity of the factors Endogenous Characteristics and Market Characteristics, and Market Knowledge and Characteristics, whose squared correlations (respectively, $r_{c e, c m}^{2}=0.04 \mathrm{e} \mathrm{r}_{\mathrm{c}, \mathrm{cm}}^{2}=$ $0.03)$ are considerably lower than the AEV values of each of the factors ( 0.64 e 0.81 respectively).

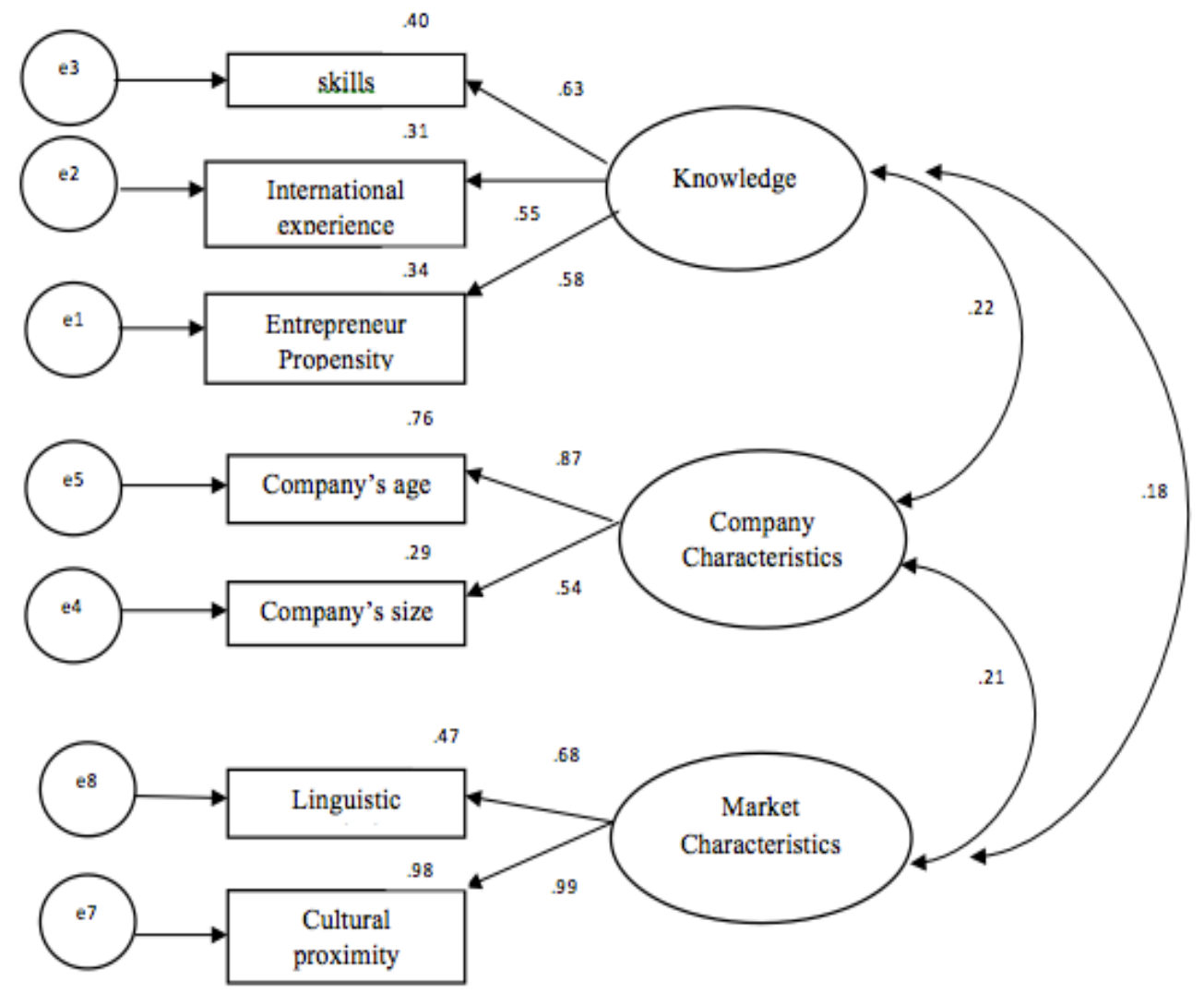

Figure 1. Tri-Factorial Model of the Factors Enhancing Entrepreneurial Internationalization Own elaboration (Source: Output AMOS) $(X 2 / D F=1.674, C F I=0.981, G F I=0.984, R M S E A=0.047, P$ $[R M S E A \leq .05]=0.513 E M E C V I=0.172)$

The removal of the variable Network of Contacts in the host country may seem to suggest that this is a variable with little importance for the entrepreneurs and therefore to contradict the results obtained in the sample (descriptive analysis of the data). However, the variable was removed from the model because it presented correlations (although weak) with another of the latent factors (the Knowledge) and because it also presented a relatively low factorial weight $(0.48)$. That result can be interpreted in a way that is opposed to that initially suggested. As observed in the sample this is one of the variables with higher Modal value and with lower variance, thus confirming that the great majority of entrepreneurs attribute high importance to this variable. This result may mean that both entrepreneurs who give more attention to "Knowledge" and those who care about "Physical and psychological distances" attach great importance to the variable Network of Contacts in the host country.

\section{CONCLUSIONS}

This study allows presenting a Theoretical Measurement Model for the Factors Enhancing the Internationalization of Business. From the results of the CFA, it was possible to confirm the structural patterns found, that is, to ensure that the three latent factors defined in the EFC are the ones that represent, for Portuguese entrepreneurs, the factors that enhance the business internationalization. The factorial structure found evidences the importance of factors such as Relational Networks, as suggested by [10] [4] [12] [41]. It is also consistent with the Theory of Relational Networks or Network Theory and also with the Vicarious Learning approach of [5]. It coincides with the specific 
competences of the collaborators, defended by Human Capital Theory, by the socio-cognitive career theory, and also by Resource-Based View [13]. The International Collaborators Experience is in line with [6] [33] in the approach to Experiential Learning. The entrepreneurial propensity, and taking risks on the part of the Employees and Management, as affirmed by the socio-cognitive career theory, the Population Ecology approach [24], and the Congenital Learning approach is consistent with studies by [10] [25]. As mentioned previously, all these theories are added in the Theory of International New Ventures [30] and in the Strategic Choice View [5], approaches that we choose as basis for this work and that support the Model of theoretical measure presented.

This study assumes the importance of studying the relationship of potential moderation of the relationship between satisfaction with life in general and satisfaction with working life in particular. Based on the data obtained in this study, it is interesting to promote studies that allow us to indicate if the Employees develop and persist goal oriented in domains of activity in which they see themselves as effective and in which they perceive as likely to achieve positive results. Yet, how do work and other life roles assume themselves as relevant in the life of a collaborator; how career choices are articulated in the lives of these employees. How can individuals become self-directional in their development process, what are the factors in addition to the personal traits that stimulate choice and career change. Finally, how career competencies are enhanced and how poor career performance can be resolved, and how the interests of employees are differentiated, intensified, and changed over time.

\section{REFERENCES}

[1] L. P. Dana, and R. W. Wright, "Emerging paradigms on international entrepreneurship," in Handbook of Research on International Entrepreneurship (L. P. Dana, eds.), pp. 3-15, Northampton, MA, USA: Edward Elgar, 2004.

[2] S. L. Teixeira, "Estratégias de Internacionalização: Um Modelo para as PME. Aplicação à indústria portuguesa do calçado," in Actas de las XIII Jornadas Hispano-Lusas de Gestión Científica, volumen I, pp.505-514, Oragnización de Empresas: Estrategia Universidad de Santiago de Compostela, Facultad de Administración e Dirección de Empresas, Lugo, 2003.

[3] M. A. Seifriz, S. M. Gondim, and M. E. Pereira, "Internationalization and Networks in Small and Medium-sized Enterprises: the role of ethnic ties," Revista Brasileira de Gestão de Negócios, vol. 16, no. 50, pp. 5-24, 2014.

[4] J. Santos, M. Ferreira, and N. Reis, "Industrial network membership: reducing psychic distance hazards in internationalization of firms," Revista Brasileira de Gestão de Negócios, vol. 14, no. 45, pp. 438-452, 2012.

[5] D. De Clercq, H. Sapienza, R. Yavuz, and L. Zhou, "Learning and knowledge in early internationalization research: Past accomplishments and future directions," Journal of Business Venturing, vol. 27, pp.143-165, 2012.

[6] J. Bruneel, H. Yli-Renko, and B. Clarysse, "Learning from experience and learning from others: how congenital and inter organizational learning substitute for experiential learning in young firm internationalization," Strategic Entrepreneurship Journal, vol. 4 , pp. 164-182, 2010.

[7] C. Brito, and S. Lorga, Marketing Internacional. Porto: Sociedade Portuguesa de Inovação, 1999.

[8] V. C. Simões, Estratégias de Internacionalização das Empresas Portuguesas ICEP. Investimentos, Comércio e Turismo de Portugal, 1997.

[9] J. Johanson, and L. Mattsson, "Internationalization in industrial systems: A network," in, Strategies In Global Competition (N. Hood, and J. E. Vahlne, eds.), pp. 287-314, New York: Croom Helm, 1988.

[10] J. Johanson, and J. E. Vahlne, "The Uppsala internationalization process model revisited: From liability of foreignness to liability of outsidership," Journal of International Business Studies, vol. 40, pp. 1411-1431, 2009.

[11] P. Rebocho, A Internacionalização das PME no Período 2008/2010. Lisboa: Instituto Superior de Contabilidade e Administração de Lisboa, 2010. 
[12] R. Korsakienè, and M. Tvaronavičienè, "The internationalization of SMEs: an integrative approach," Journal of business economics and management, vol.13, no. 2 , pp. 294-307, 2012.

[13] R. Javalgi, and P. Todd, "Entrepreneurial orientation, management commitment, and human capital: The internationalization of SMEs in India," Journal of Business Research, vol. 64, pp. 1004-1010, 2011.

[14] E. Torrens, M. Amal, and G. Tontini, "Determinantes do desempenho exportador de pequenas e médias empresas manufatureiras brasileiras sob a perspectiva da visão baseada em recursos e do modelo de uppsala," Revista Brasileira de Gestão de Negócios, vol. 16, no. 53, pp. 511-539, 2014.

[15] A. Bandura, Self-efficacy: The exercise of control. New York: W.H. Freeman, 1997.

[16] G. Hackett, "Self-efficacy and career choice and development," in Self-efficacy in changing societies (A. Bandura, eds.), pp. 232-258, New York: Cambridge University Press, 1995.

[17] G. Hackett, and R. W. Lent, "Theoretical advances and current inquiry in career psychology," in Handbook of Counseling Psychology (S. D. Brown and R. W. Lent, eds.), pp. 419-452, New York: Wiley, 1992.

[18] J. L. Swanson, and P. A. Gore, "Advances in vocational psychology theory and research," in Handbook of counseling psychology (S. D. Brown and R. W. Lent, eds.), pp. 233-269, New York: Wiley and Sons, 2000.

[19] R. W. Lent, S. D. Brown, and G. Hackett, "Social cognitive career theory," in Career choice and development (D. Brown and Associates, eds.), pp. 255-311, San Francisco: Jossey- Bass, 2002.

[20] R. W. Lent, S. D. Brown, J. Schmidt, B. Brenner, H. Lyons, and D. Treistman, "Relation of contextual suports and barriers to choice behavior in engineering majors: Test of alternative social cognitive models," Journal of Counseling Psychology, vol. 50, pp. 458-465, 2003.

[21] R. W. Lent, S. D. Brown, and G. Hackett, "Toward a unifying social cognitive theory of career and academic interest, choice, and performance," Journal of Vocational Behavior, vol. 45, pp. 79-122, 1994

[22] R. W. Lent, "Toward a unifying theoretical and practical perspective on well-being and psychosocial adjustment" Journal of Counseling Psychology, vol. 51, no. 4, 482-501, 2004.

[23] A. B. Ibrahim, "Internationalization: motive and process," in Handbook of Research on International Entrepreneurship (L. P. Dana eds.), pp. 129-136, Northampton, MA, USA: Edward Elgar, 2004.

[24] S. Fernhaber, and D. Li, "International exposure through network relationships: Implications for new venture internationalization," Journal of Business Venturing, vol. 28, pp. 316-334, 2013.

[25] B. M. Oviatt, and P. P. McDougall, "Defining international entrepreneurship and modeling the speed of internationalization," Entrepreneurship: Theory and Practice, vol. 29, no. 5, pp. 537553, 2005.

[26] G. Knight, and S. T. Cavusgil, "Innovation, organizational capabilities, and the bornglobal firm," Journal of International Business Studies, vol. 35, no. 2, pp. 124-141, 2004.

[27] P. McDougall, S. Shane, and B. M. Oviatt, "Explaining the formation of international new ventures: The limits of theories from international business research," Journal of Business Venturing, vol. 9, no 6, pp. 469-487, 1994.

[28] J. Johanson, and J. E. VahIne, "The Internationalization Process of the Firm: A Model of Knowledge Development and Increasing Foreign Market Commitments," Journal of International Business Studies, vol. 8, pp. 23-32, 1977.

[29] J. Johanson, and J. E. Vahlne, "The mechanism of internationalization," International Marketing Review, vol. 7, no. 4, pp. 11-24, 1990.

[30] P. McDougall, and B. M. Oviatt, "International entrepreneurship: the intersection of two research paths," Academy of Management Journal, vol. 43, no. 5, 902-906, 2000. 
[31] D. Cumming, H. Sapienza, D. Siegel, and M. Wright, "International entrepreneurship: managerial and policy implications," Strategic Entrepreneurship Journal, vol. 3, no. 4, pp. 283296, 2009.

[32] D. De Clercq, H. Sapienza, and H. Crijns, "The internationalization of small and medium-sized firms: The role of organizational learning effort and entrepreneurial orientation," Small Business Economics, vol. 24, no. 4, pp. 409-419, 2005.

[33] C. Schwens, and R. Kabst, "Entry Learning, Age at Internationalization, and Foreign-Venture Performance of Young Technology Firms," Schmalenbach Business Review, vol. 63, no. 3, 2011.

[34] W. Burpitt, and D. Rondinelli, "Export decision-making in small firms: The role of organizational learning," Journal of World Business, vol. 33, no. 1, pp. 51-68, 1998.

[35] A. Kocak, and T. Abimbola, "The effects of entrepreneurial marketing on born global performance," International Marketing Review, vol. 26, no. 4, pp. 439-452, 2009.

[36] J. Casillas, A. Moreno, F. Acedo, and M. Gallego, "An integrative model of the role of knowledge in the internationalization process," Journal of World Business, vol. 44, no. 3, 311322, 2009.

[37] N. Coviello, "The network dynamics of international new ventures," Journal of International Business Studies, vol. 37, no. 5, pp. 713-731, 2006.

[38] Z. Breda, "Redes Relacionais e a Internacionalização da Economia do Turismo: O caso do investimento Português no estrangeiro no sector hoteleiro," Unpublished PhD Thesis: Universidade de Aveiro, 2010.

[39] J. Marôco, Análise de Equações Estruturais: Fundamentos teóricos, Software \& Aplicações. Pêro Pinheiro: ReportNumber, 2014.

[40] C. Fornell, and D. Larcker, "Evaluating structural equation models with unobservable variables and measurement error," Journal of Marketing Research vol. 18, no. 1, 39-50, 1981.

[41] A. C. Zen, J. E. Fensterseifer, J. E., and F. Prévot, "The impact of export performance resources of companies belonging to clusters: A study in the French winery industry," Revista Brasileira de Gestão de Negócios, vol 16, no. 52, pp. 1444-1463, 2014. 